\title{
Postnatal depression in women after unsuccessful attempted abortion
}

Ana Bernarda Ludermir, Ricardo Araya, Thália Velho Barreto de Araújo, Sandra Alves Valongueiro

and Glyn Lewis

\section{Summary}

A population-based cohort study investigated postnatal depression in Brazilian women who attempted an abortion. Participants' views and actions on abortion were assessed during pregnancy and postnatal depression was evaluated with the Edinburgh Postnatal Depression Scale. An

unsuccessful abortion attempt was associated with postnatal depression (adjusted $\mathrm{OR}=1.6,95 \% \mathrm{Cl}$ 1.0-2.5). In Brazil abortion is illegal under most circumstances.

\section{Declaration of interest}

None.
The mental health implications of abortion remain unclear. ${ }^{1,2}$ Major et al concluded that women who had a legal abortion following unintended pregnancy did not have a higher risk of mental health problems than women whose unplanned pregnancy was carried to term. ${ }^{3}$ In contrast, Fergusson et al found that women who had had an abortion were more likely to have mental disorder. ${ }^{4}$ Findings from studies in countries where abortion is legal and readily available cannot be compared with those from settings where it is almost impossible to obtain a legal abortion. ${ }^{1}$ In countries with liberal abortion laws, women who carry an unwanted pregnancy to term choose to do so; this represents a group distinct from women living in countries where this choice is unavailable. In a previous cross-sectional study we found that women who unsuccessfully attempted an abortion in their current pregnancy had an increased prevalence of anxiety and depression during the antenatal period. ${ }^{5}$ We report here the results of a longitudinal study that investigated postnatal depression in women who unsuccessfully attempted an abortion during pregnancy.

\section{Method}

A cohort study was conducted in an area with a high proportion of low-income families in Recife, northeastern Brazil. The study population $(n=1133)$ consisted of all pregnant women aged 1849 years in their third trimester of pregnancy who had registered in the Primary Health Care Program (PHCP). They were identified from antenatal care records in primary care and from the records of community health workers. This allowed inclusion of those not receiving antenatal care at a PHCP unit. Data were collected from July 2005 to December 2006; postnatal interviews took place in the period May to December 2006. The median length of follow-up after delivery was 8.1 months (interquartile range 5.2-10.2). Postnatal depression was evaluated using the Brazilian version of the Edinburgh Postnatal Depression Scale (EPDS), ${ }^{6,7}$ with a score of 12 or more on the scale defining a case. ${ }^{7,8}$ Women's views and actions on abortion were recorded during the antenatal interview. Participants were asked whether they had wanted an abortion at any time during their current pregnancy, and those who answered positively were asked if they had attempted an abortion. A question related to the method of terminating the pregnancy was used to check for consistency of response. Potentially confounding variables were assessed: age, ethnicity, currently living with a partner, years of schooling, employment, financial hardship and unwanted pregnancy. The women were also asked about their perception of the father's acceptance of the pregnancy (content/accepted/indifferent; did not like/other; suggested an abortion) and about their experience of specific acts of psychological, physical and sexual violence by a current or former partner. ${ }^{9}$ Common mental disorders were assessed in the antenatal period with the 20-item Self-Reporting Questionnaire (SRQ-20). ${ }^{10}$ Women were asked about their personal history of mental illness. Social support was assessed with the Medical Outcomes Study Social Support Survey. ${ }^{11}$

We used Stata version 10 for Windows for the analysis. Logistic regression was used to estimate odds ratios and 95\% confidence intervals of the association between attempting an abortion and postnatal depression. Linear regression was used to investigate mean differences in EPDS scores at different levels of exposure.

\section{Results}

The study response rate was high, with 1057 women completing the postnatal interview. This represents $94.3 \%$ of pregnant women who completed their assessments during pregnancy (98.9\% of all 1133 eligible women). Baseline data are reported elsewhere. ${ }^{5}$ Women who attempted an abortion were more likely to have had an unwanted pregnancy and to report a history of mental illness, and had a prevalence of an SRQ-20 score of 8 or above of $63.6 \%$ (95\% CI 55.4-71.2) during pregnancy. Of the 1037 women who had complete data on all variables included in the model, $13.5 \%$ had attempted an abortion during pregnancy. There was a clear association between postnatal depression and attempted abortion, although it was attenuated after adjustment $(\mathrm{OR}=1.59,95 \%$ CI 1.0-2.5). Symptoms assessed with the EPDS were more common among those who had attempted an abortion (Table 1), both before and after adjustment. The most important individual confounders were antenatal SRQ-20 score, which reduced the odds ratio from 2.53 (95\% CI 1.7-3.7) to 1.87 (95\% CI 1.2-2.8), and unwanted pregnancy, which reduced it to 2.26 (95\% CI $1.5-3.4)$.

\section{Discussion}

As far as we are aware this is the first population-based cohort study designed to investigate postnatal depression among women who unsuccessfully attempted an abortion in a country where abortion is in most cases illegal. Our results indicate that women who attempted an abortion had an increased risk of postnatal depression compared with women who had merely thought about an abortion and also presumably carried an unwanted pregnancy.

Several strengths of this study need to be highlighted. Our large community sample is fairly representative of poor women in this setting. We had a high response rate. Also we were able 
Table 1 Odds ratios for postnatal depression and Edinburgh Postnatal Depression Scale (EPDS) scores categorised by women's views and actions on abortion

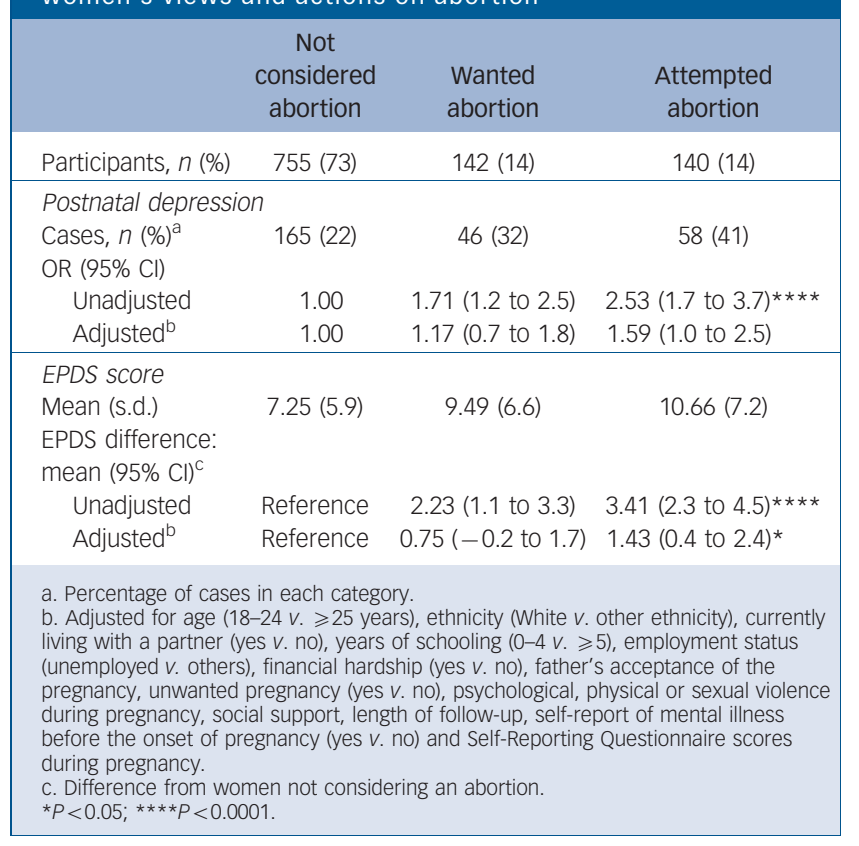

to adjust for a large number of possible confounding variables. Some limitations are worth considering. We found a fairly high prevalence of postnatal depression but our estimates are consistent with previous studies in low- and middle-income countries, ${ }^{8}$ including Brazil. ${ }^{12}$ The EPDS threshold used was established in previous validation studies with similar populations. ${ }^{7,8}$ The Edinburgh scale measures current symptoms of depression, so women might have experienced depression earlier in the postpartum period but have been asymptomatic by the time of the interview. Although longer and more detailed assessments of postnatal depression exist, we would expect any measurement error to be random in relation to considering an abortion and this would reduce the size of an observed association.

Brazilian law allows abortion only when there is a threat to the woman's life or in the case of rape. In view of this, women may be reluctant to disclose a pregnancy that they wish to terminate. ${ }^{13}$ However, we used a questionnaire that takes a non-judgemental and more accepting approach to this sensitive subject. Interviews were conducted by women in a private environment. The ascertainment of postpartum depression was made after the assessment of the exposure status; thus we would expect any measurement error in relation to abortion to be random in relation to the outcome.

A recent study has suggested that abortion is associated with a small increase in the risk of mental disorder in comparison with women who have never had a child. ${ }^{4}$ Unfortunately we do not have information on women who successfully aborted.

Women who attempted an abortion might experience poor mental health for a number of reasons. Attempting an abortion reflects unhappiness with pregnancy. However, delivering and parenting an unwanted child may be a source of continuous unhappiness. ${ }^{14}$ This is not a minor problem in Brazil, where it is estimated that $46 \%$ of all births between 2001 to 2006 were unplanned $\left(60 \%\right.$ in our cohort). ${ }^{15}$ It has been suggested that women with a history of mental illness are more prone to depression after an unwanted pregnancy regardless of whether they abort or carry the pregnancy to term; ${ }^{16}$ however, we found no association between unwanted pregnancy and self-reported mental illness before pregnancy (data not shown). Furthermore, the association between attempting an abortion and postpartum depression was still present after adjustment for antenatal SRQ-20 score and unwanted pregnancy, suggesting that this association is independent of both antenatal mental illness and unwanted pregnancy. We suggest that this result may be generalisable to other countries where abortion is difficult or impossible to obtain. Our findings support arguments to improve the coverage and quality of family planning programmes and safe abortion.

\section{Ana Bernarda Ludermir, PhD, Federal University of Pernambuco, Recife, Brazil; Ricardo Araya, PhD, Academic Unit of Psychiatry, University of Bristol, Bristol, UK ; Thália Velho Barreto de Araújo, PhD, Sandra Alves Valongueiro, PhD, Federa University of Pernambuco, Recife, Brazil; Glyn Lewis, PhD, Academic Unit of Psychiatry, University of Bristol, Bristol, UK \\ Correspondence: Dr Ana Bernarda Ludermir, Programa de Pós-Graduação Integrado em Saúde Coletiva, Universidade Federal de Pernambuco, Avenida Professor Moraes Rêgo, s/n. Hospital das Clínicas, Bloco E, $4^{\circ}$ andar, Cidade Universitária, Recife, C.E.P.: 50670-901, PE - Brazil. Email: abl@ufpe.br \\ First received 21 Dec 2009, final revision 12 Oct 2010, accepted 3 Nov 2010}

\section{Funding}

The study was funded by the Ministry of Health/Decit and Conselho Nacional de Desenvolvimento Científico e Tecnológico, Brazil (grant numbers 403060/2004-4 and 473545/2004-7). The funders have no involvement with the research.

\section{References}

1 World Health Organization. Mental Health Aspects of Women's Reproductive Health: A Global Review of the Literature. WHO, 2009.

2 Charles VE, Polis CB, Sridhara SK, Blum RW. Abortion and long-term mental health outcomes: a systematic review of the evidence. Contraception 2008; 78: $436-50$

3 Major B, Appelbaum M, Beckman L, Dutton MA, Russo NF, West C. Report of the APA Task Force on Mental Health and Abortion. American Psychological Association, 2008

4 Fergusson DM, Horwood L, Boden JM. Abortion and mental health disorders: evidence from a 30-year longitudinal study. Br J Psychiatry 2008; 193: $444-51$.

5 Ludermir AB, de Araújo TVB, Valongueiro SA, Lewis G. Common mental disorders in late pregnancy in women who wanted or attempted an abortion. Psychol Med 2010; 40: 1467-73.

6 Cox JL, Holden JM, Sagovsky R. Detection of postnatal depression: development of the 10-item Edinburgh Postnatal Depression Scale. Br J Psychiatry 1987; 150: 782-6.

7 Cantilino A, Sougey E. Escalas de triagem para depressão pós-parto. Neurobiologia 2003; 66: 75-9.

8 Patel V, Rodrigues M, Desouza N. Gender, poverty and postnatal depression: a study of new mothers in Goa, India. Am J Psychiatry 2002; 159: 43-7.

9 Ludermir AB, Schraiber LB, d'Oliveira AFPL, França-Junior I, Jansen HA. Violence against women by their intimate partner and common mental disorders. Soc Sci Med 2008; 66: 1008-18.

10 Harding TW, Arango MV, Climent CE, Ibrahim HH, Ladrido-Ignacio L, Murthy RS, et al. Mental disorders in primary health care: a study of their frequency and diagnosis in four developing countries. Psychol Med 1980; 10: 231-41.

11 Sherbourne CD, Stewart AL. The MOS social support survey. Soc Sci Med 1991; 32: 705-14.

12 Figueira $\mathrm{P}$, Corrêa H, Malloy-Diniz L, Romano-Silva MA. Edinburgh Postnatal Depression Scale for screening in the public health system. Rev Saude Publica 2009; 43 (suppl 1): 79-84.

13 Osis MJD, Hardy E, Faúndes A, Rodrigues T. Dificuldades para obter informações da população de mulheres sobre aborto ilegal. Rev Saude Publica 1996; 30: 444-51.

14 Villela W, Oliveira EM, Silva RC. Aborto e saúde mental. In Direito de Decidir: Múltiplos Olhares Sobre o Aborto (ed MM Maia): 43-66. Autêntica Editora, 2008.

15 Ministério da Saúde. Pesquisa Nacional de Demografia e Saúde da Criança e da Mulher - PNDS 2006: Dimensões do Processo Reprodutivo e da Saúde da Criança [The Demographic Health Survey]. Ministério da Saúde, 2009 (http:// bvsms.saude.gov.br/bvs/publicacoes/pnds_crianca_mulher.pdf).

16 Major B, Cozzarelli C, Cooper ML, Zubek J, Richards C, Wilhite M, et al. Psychological responses of women after firsttrimester abortion. Arch Gen Psychiatry 2000; 57: 777-84. 